\title{
Aromatizing Olefin Metathesis by Ligand Isolation inside a Metal- Organic Framework
}

\author{
Nicolaas A. Vermeulen, Olga Karagiaridi, Amy A. Sarjeant, Charlotte L. Stern, Joseph T. Hupp,* \\ Omar K. Farha,* and J. Fraser Stoddart* \\ Department of Chemistry, Northwestern University, 2145 Sheridan Road, Evanston, Illinois 60208, United States
}

\section{Supporting Information}

ABSTRACT: The aromatizing ring-closing metathesis has been shown to take place inside an extended porous framework. Employing a combination of solvent-assisted linker exchange and postsynthesis modification using olefin metathesis, the noninterpenetrated SALEM-14 was formed and converted catalytically into PAH-MOF-1 with polycyclic aromatic hydrocarbon (PAH) pillars. The metal-organic framework in SALEM-14 prevents "intermolecular" olefin metathesis from occurring between the pillars in the presence of the first generation HoveydaGrubbs catalyst, while favoring the production of a PAH, which can be released from the framework under acidic conditions in dimethylsulfoxide.

$\mathrm{R}$ ecently, metal-organic frameworks (MOFs) have attracted $^{1}$ a lot of attention as a unique class of highly adaptive nanoporous materials. The ability of MOFs to incorporate a wide variety of chemical functionality, on account of their easily altered organic struts, has resulted ${ }^{2}$ in their exploration for purposes such as gas storage, ${ }^{3}$ gas separation, ${ }^{4}$ chemical sensing, ${ }^{5}$ catalysis, ${ }^{6}$ and drug delivery. ${ }^{7}$ Although de novo syntheses of MOFs with a range of different struts, which facilitate the introduction of functionality, have been highly successful, many metal/strut combinations react in unpredictable ways ${ }^{8}$ and lead to undesirable byproducts. To overcome these vagaries and achieve the formation of desired frameworks, two alternative synthetic protocols have emerged: they are (i) postsynthesis modification ${ }^{9}$ (PSM) and (ii) solvent-assisted linker exchange ${ }^{10}$ (SALE). PSM refers to chemical modifications of the organic struts in MOFs to either unmask ${ }^{11}$ reactive functionality or introduce ${ }^{12}$ functional groups which do not survive (or disrupt) MOF synthesis and has become a commonor-garden approach to generate much sought-after extended frameworks. It is worthy of note that few reports ${ }^{13}$ describe $\mathrm{C}-\mathrm{C}$ bond-forming reactions by PSM. By contrast, SALE allows for the exchange of struts in readily obtainable MOFs to produce ${ }^{14}$ extended frameworks with more chemically diverse and useful properties. These two fundamentally different protocols are not mutually exclusive and, employed in concert, can be used to generate metal/strut combinations in MOFs that are not attainable by any other means.

The ability of the olefin metathesis popularized by the extensive use ${ }^{15}$ of Grubbs catalysts, ${ }^{16}$ to transform the molecular structure, is both unique and chemically enabling. ${ }^{17}$ In addition to the extensive use of this reaction in the fields of polymer chemistry ${ }^{15 b}$ and materials science, ${ }^{15 b}$ olefin metathesis has been employed in the synthesis of numerous complex small-molecule compounds. $^{15 a}$ One example ${ }^{18}$ of this ubiquitous structural transformation is the generation (Scheme 1) of polycyclic

Scheme 1. Use of Grubbs Catalyst To Make PAHs ${ }^{18 b}$

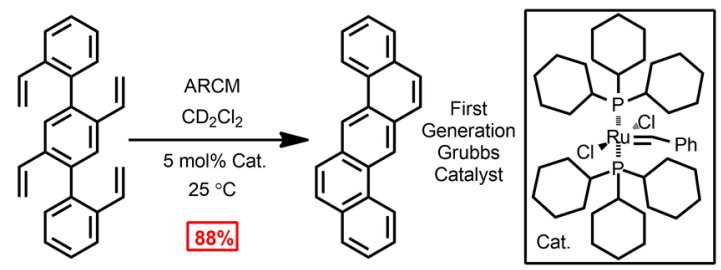

aromatic hydrocarbons (PAHs) from starting materials containing vinyl benzene units. It is known ${ }^{19}$ as the aromatizing ringclosing metathesis (ARCM); its use inside MOFs would enable the preparation of new extended frameworks employing PSM and would permit the formation of exotic PAHs as isolated linkers in MOFs.

To aid and abet the efficient, rapid synthesis of large-pore, noninterpenetrated frameworks containing PAHs, we turned our attention to SALE methodology. ${ }^{10}$ We employed the preformed noninterpenetrated framework ${ }^{20}$ Br-YOMOF which is constructed (Scheme 2) from $\mathrm{Zn}\left(\mathrm{NO}_{3}\right)_{2}$ and two organic

Scheme 2. Synthesis of Noninterpenetrated Br-YOMOF

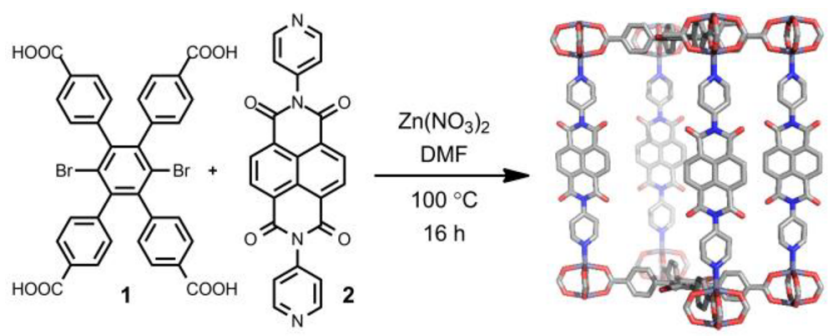

components: (1) the tetracarboxylic acid ligand $\mathbf{1}$ (with two Br-atoms ${ }^{21}$ on the central phenylene ring to block interpenetration) which forms $2 \mathrm{D}$ sheets with $\mathrm{Zn}^{2+}$ dimers and (2) the dipyridyl strut 2 which links the $2 \mathrm{D}$ sheets by coordinating to the zinc paddlewheel clusters forming perpendicular pillars separating the 2D layers. Following the synthesis of Br-YOMOF,

Received: July 19, 2013

Published: September 18, 2013 
Scheme 3. Synthesis of SALEM-13 and Olefin Metathesis of 3 and SALEM-13
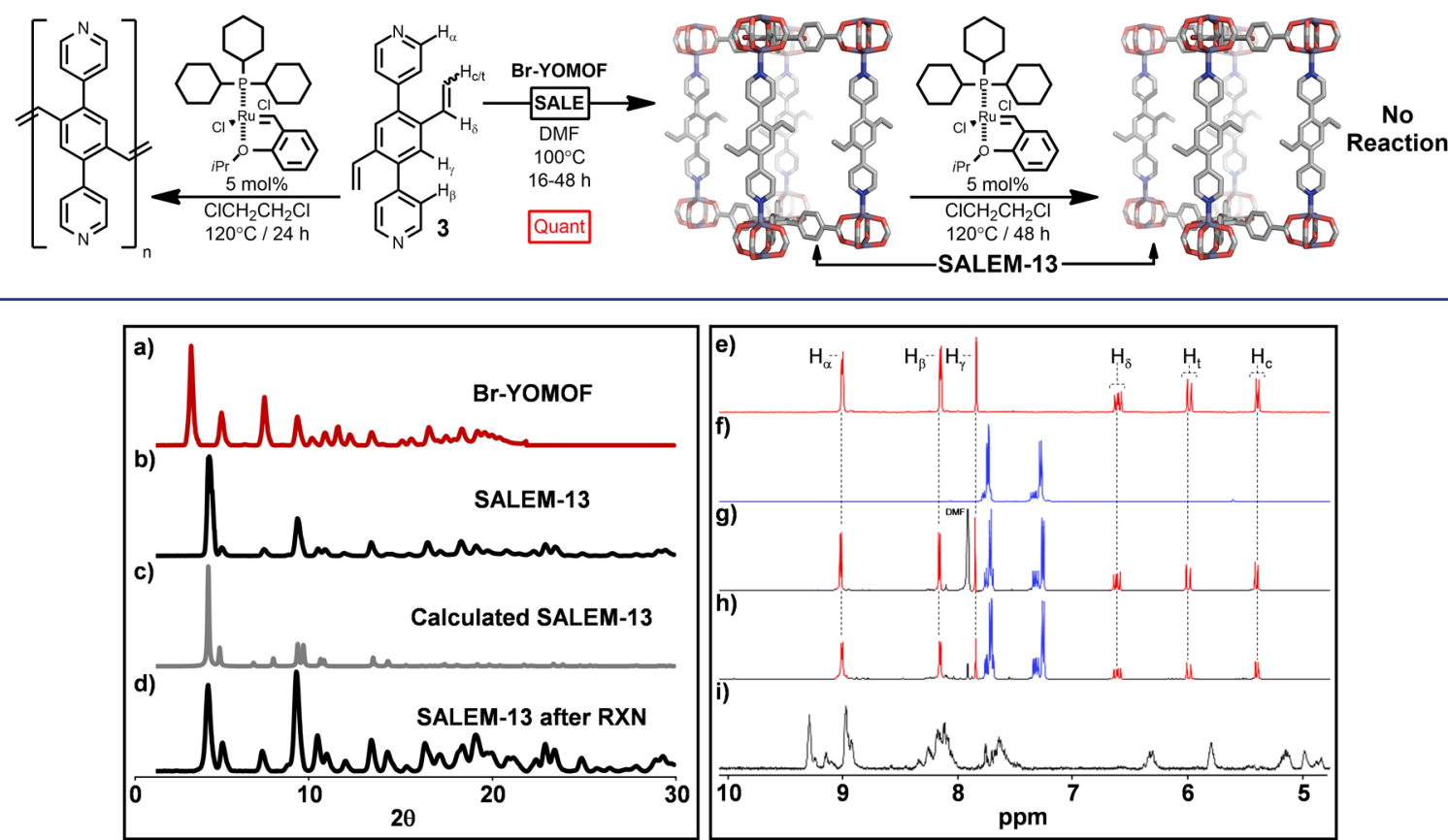

Figure 1. (a) Experimental PXRD of Br-YOMOF, (b) experimental PXRD of SALEM-13 as synthesized, (c) calculated PXRD of SALEM-13, and (d) experimental PXRD of SALEM-13 after olefin metathesis. The partial ${ }^{1} \mathrm{H}$ NMR spectra of (e) the divinyldipyridyl linker 3, (f) the tetracarboxylic acid ligand 1, (g) regenerated ${ }^{22}$ products $(1$ and 3$)$ from SALEM-13, (h) regenerated ${ }^{22}$ products (1 and 3), following treatment $\left(120^{\circ} \mathrm{C} / 48 \mathrm{~h}\right)$ of SALEM13 in DCE with the first generation Hoveyda-Grubbs catalyst, (i) the crude reaction mixture, following treatment $\left(120^{\circ} \mathrm{C} / 24 \mathrm{~h}\right)$ of 3 in DCE with the first generation Hoveyda-Grubbs catalyst. All spectra were recorded in $\mathrm{CD}_{3} \mathrm{SOCD}_{3}$ containing a few drops of $\mathrm{D}_{2} \mathrm{SO}_{4}$ at $298 \mathrm{~K}$ on a $500 \mathrm{MHz}$ spectrometer.

the pillars can be exchanged for different dipyridyl linkers employing SALE to provide access to a noninterpenetrated framework without having to resort to de novo synthesis.

One of the major benefits of doing chemistry inside a highly organized porous material is the unique ability of a rigid, extended framework to site-isolate reactive functional groups and thus prevent unproductive "intermolecular" chemistry. To test this concept, we elected to make a strut, which does not, on its own, undergo intramolecular RCM, but instead only produces poorly defined polymeric material when exposed to an olefin metathesis catalyst. The divinylpyridyl linker 3 was prepared (see Supporting Information (SI)) and subjected to SALE to produce (Scheme 3, Figure 1a,b) SALEM-13. The powder X-ray diffraction (PXRD) pattern of SALEM-13 confirms (Figure 1b) its crystallinity. Furthermore, after the unit cell had been indexed, it was evident that a reduction in its size had taken place during the SALE performed on Br-YOMOF to afford SALEM13. The observed [001] peak in Br-YOMOF and SALEM-13 corresponds to a reflection originating from the $c$-axis direction along which the dipyridyl pillars lie. The shift from $2 \theta=3.94$ (Figure $1 \mathrm{~b}$ ) in Br-YOMOF to $2 \theta=4.80$ (Figure 1a) in SALEM13 points to the incorporation of a shorter pillar. ${ }^{23}$

In a dichloroethane (DCE) solution, exposure of 3 to the first generation Hoveyda-Grubbs (HG) catalyst at $120{ }^{\circ} \mathrm{C}$ leads to the formation (Scheme 3 ) of the expected polymeric product as indicated by the broad resonances (Figure 1i) in its ${ }^{1} \mathrm{H}$ NMR spectrum. By contrast, the two vinyl groups in the pillars of the porous extended framework provided by SALEM-13 revealed no reactivity at all (Figure $1 \mathrm{e}-\mathrm{h}$ ), even after prolonged exposure to the same HG catalyst under identical conditions. This observation is consistent with the hypothesis that the MOF site-isolates the potentially reactive olefins, preventing them from undergoing "intermolecular" metathesis. In this knowledge, we undertook the preparation (Scheme 4) of the tetravinyldipyridyl strut 6 which, in principle, should be able to undergo ARCM.

Scheme 4. Synthesis of the Tetravinyldipyridyl Strut 6

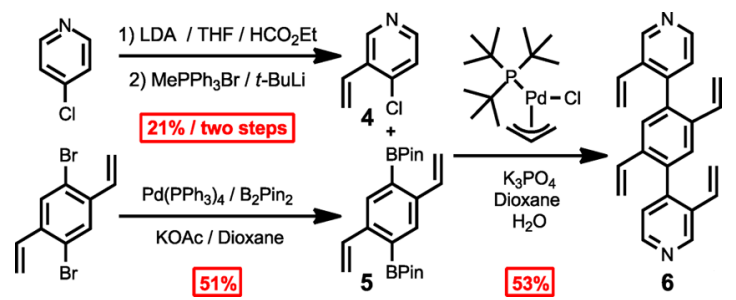

The pyridyl portions of 6 were prepared in two steps from 4chloropyridine. Its thermodynamic deprotonation using lithium diisopropylamide (LDA), followed by quenching with ethyl formate before carrying out a Wittig reaction with $\mathrm{MePPh}_{3} \mathrm{Br}$, produced $^{24}$ the desired intermediate 4 in $21 \%$ yield over the two steps (Scheme 4). 1,4-Dibromo-2,5-dimethylbenzene was further brominated (NBS, $\mathrm{C}_{6} \mathrm{H}_{6}$ ), affording 1,4-dibromo-2,5bis(bromomethyl)benzene which was treated with $\mathrm{PPh}_{3}$ to generate the diphosphonium bromide before reacting it with paraformaldehyde to give 1,4-dibromo-2,5-divinylbenzene. A subsequent Miyaura borylation afforded ${ }^{25}$ the intermediate 5 in $34 \%$ yield over the three steps. The tetravinyldipyridyl strut 6 was obtained in 53\% yield as a result of carrying out a Suzuki coupling between 4 and 5 using palladium ( $\pi$-allylchloride)tri(tertbutyl)phosphine) as the catalyst. ${ }^{26} \mathrm{We}$ attempted to prepare (Scheme 5) the PAH 7 in DCE at $120{ }^{\circ} \mathrm{C}$, using the first generation $\mathrm{HG}$ catalyst. The result was only insoluble polymeric 
Scheme 5. Synthesis of SALEM-14 and Olefin Metathesis of 6 and SALEM-14
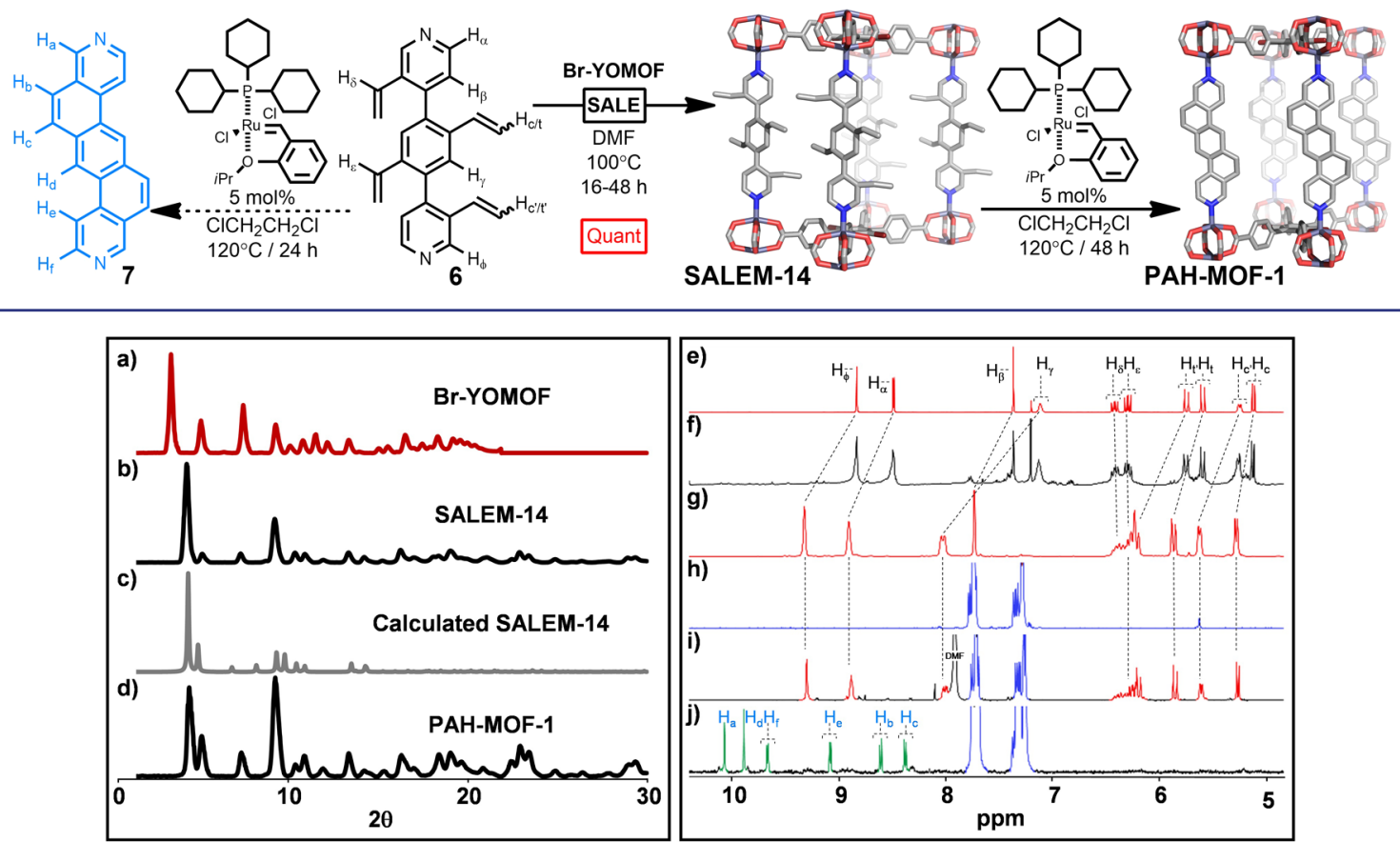

Figure 2. (a) Experimental PXRD of Br-YOMOF, (b) experimental PXRD of SALEM-14 as synthesized, (c) calculated PXRD of SALEM-14, and (d) experimental PXRD of PAH-MOF-1 after ARCM. The partial ${ }^{1} \mathrm{H}$ NMR spectra of (e) the tetravinyldipyridyl linker 6 in $\mathrm{CDCl}_{3}$; (f) the crude reaction mixture from the homogeneous ARCM of 6 following treatment $\left(120^{\circ} \mathrm{C} / 24 \mathrm{~h}\right)$ with the first generation Hoveyda-Grubbs catalyst in $\mathrm{CDCl}_{3}$, showing some broadening of the resonances as a result of some intermolecular polymerization; $(\mathrm{g})$ the tetravinyldipyridyl linker 6 in $\mathrm{CD}_{3} \mathrm{SOCD}_{3} / \mathrm{D}_{2} \mathrm{SO}_{4} ;(\mathrm{h})$ the tetracarboxylic acid ligand 1 in $\mathrm{CD}_{3} \mathrm{SOCD}_{3} / \mathrm{D}_{2} \mathrm{SO}_{4} ;(\mathrm{i})$ regenerated ${ }^{22}$ products $(1$ and 6$)$ from SALEM-14 dissolved in $\mathrm{CD}_{3} \mathrm{SOCD}_{3} / \mathrm{D}_{2} \mathrm{SO}_{4} ;$ and $(\mathrm{j})$ regenerated ${ }^{22}$ products $(1$ and 7$)$ from PAH-MOF-1 dissolved in $\mathrm{CD}_{3} \mathrm{SOCD}_{3} / \mathrm{D}_{2} \mathrm{SO}_{4}$, following treatment $\left(120^{\circ} \mathrm{C} / 48 \mathrm{~h}\right)$ of SALEM-14 in DCE with the first generation Hoveyda-Grubbs catalyst. All spectra were recorded at $298 \mathrm{~K}$ on a $500 \mathrm{MHz}$ spectrometer.

material: no 7 could be detected in the reaction mixture. This outcome was hardly surprising as the intermolecular polymerization could be favored under these conditions. It should be noted that ruthenium catalysts employed in metathesis may be poisoned by soft donors, including pyridine. ${ }^{27}$ If, however, the tetravinyldipyridyl strut is converted into the pillars of an MOF, then the pyridyl nitrogen atoms in $\mathbf{6}$ will become strongly coordinated to the dinuclear $\mathrm{Zn}^{2+}$ nodes and so will be unable to interfere with the ARCM. Moreover, the extended structure of the MOF prevents the undesired polymerization between tetravinyldipyridyl pillars which characterizes the reaction of 6 in solution.

Thus, employing SALE, strut $\mathbf{6}$ was incorporated into the $\mathbf{B r}$ YOMOF architecture, resulting (Scheme 5, Figure 2a,b) in the production of SALEM-14 with near-quantitative conversion. The SALE reaction was monitored ${ }^{22}$ by ${ }^{1} \mathrm{H}$ NMR spectroscopy to ensure complete exchange of the precursor ligand, and the new extended structure was analyzed (Figure $2 \mathrm{~b}$ ) by PXRD and shown ${ }^{28}$ to be SALEM-14, an outcome which was confirmed (see the SI) by single-crystal X-ray structural analysis. SALEM14 was rinsed thoroughly with degassed DCE by soaking the crystals in the solvent for $48 \mathrm{~h}$, replacing the solvent every $12 \mathrm{~h}$ to remove any DMF remaining from the SALE reaction. The formation of the PAH 7 was achieved (Scheme 5) by PSM employing ARCM on the extended porous structure of SALEM14 with the first generation HG catalyst in DCE at $120{ }^{\circ} \mathrm{C}$ (Figure $2 \mathrm{~g}-\mathrm{j}$ ). Within one day, a significant amount of the tetravinyldipyridyl strut 6 had been converted into the PAH strut 7 , as demonstrated by the ${ }^{1} \mathrm{H}$ NMR spectroscopic monitoring procedure. $^{22}$ At the end of the second day, 6 had been converted completely into 7 (Figure $2 \mathrm{j}$ ) inside the extended structure. By contrast, the much larger ${ }^{29}$ first generation Grubbs catalyst was totally ineffective in converting the divinyldipyridyl pillars in SALEM-14 into the PAH pillars in PAH-MOF-1; that is, the mismatch between the size of a catalyst and the dimensions of the pores of an MOF can prevent catalysis from occurring.

In summary, we have demonstrated the use of a suitably sized Ru-based olefin metathesis catalyst inside an MOF to carry out a solid-state reaction in a postsynthetic fashion that cannot be accomplished in the solution phase. This proof-of-concept investigation not only demonstrates the synthetic potential of combining postsynthetic modifications with solvent-assisted linker exchange inside the MOF toolbox but also establishes the feasibility of performing "intramolecular" chemical transformations where the substrates are prevented from undergoing "intermolecular" reactions in robust, porous extended frameworks. It is clear that these frameworks are capable of exercising size selectivity toward catalysts and presumably also reagents. This kind of solid-state reaction engineering could lead to our being able to functionalize the surfaces and interiors of porous materials in a differentiated manner.

\section{ASSOCIATED CONTENT}

\section{Supporting Information}

Complete experimental details of new compounds and crystallographic data of the prepared MOFs including Crystallographic Information Files (CIF). This material is available free of charge via the Internet at http://pubs.acs.org. 


\section{AUTHOR INFORMATION}

\section{Corresponding Author}

Stoddart@northwestern.edu

\section{Notes}

The authors declare no competing financial interest.

\section{ACKNOWLEDGMENTS}

The authors thank our joint collaborators Dr. Turki S. Al-Saud and Dr. Nezar H. Khdary from the King Abdulaziz City of Science and Technology (KACST) in Saudi Arabia for their interest in this research program. O.K., J.T.H., and O.K.F. gratefully acknowledge financial support from the U.S. Dept. of Energy, Office of Science, Basic Energy Sciences program (Grant No. DE-FG02-08ER15967).

\section{REFERENCES}

(1) (a) Bloch, E. D.; Queen, W. L.; Krishna, R.; Zadrozyn, J. M.; Brown, C. M.; Long, J. R. Science 2012, 335, 1606. (b) Farha, O. K.; Eryazici, I.; Jeong, N. C.; Hauser, B. G.; Wilmer, C. E.; Sarjeant, A. A.; Snurr, R. Q.; T. Nguyen, S. T.; Yazaydın, A. O.; Hupp, J. T. J. Am. Chem. Soc. 2012, 134, 15016. (c) Canivet, J.; Aguado, S.; Schuurman, Y.; Farrusseng, D. J. Am. Chem. Soc. 2013, 135, 4195.

(2) (a) Férey, G.; Mellot-Draznieks, C.; Serre, C.; Millange, F.; Dutour, J.; Surblé, S.; Margiolaki, I. Science 2005, 309, 2040. (b) Ma, B.-Q.; Mulfort, K. L.; Hupp, J. T. Inorg. Chem. 2005, 44, 4912. (c) Hasegawa, S.; Horike, S.; Matsuda, R.; Furukawa, S.; Mochizuki, K.; Kinoshita, Y.; Kitagawa, S. J. Am. Chem. Soc. 2007, 129, 2607. (d) Nouar, F.; Eubank, J. F.; Bousquet, T.; Wojtas, L.; Zaworotko, J. M.; Eddaoudi, M. J. Am. Chem. Soc. 2008, 130, 1833. (e) Yan, Y.; Lin, X.; Yang, S.; Blake, A.; Dailly, A.; Champness, N. R.; Hubberstey, P.; Schröder, M. Chem. Commun. 2009, 1025

(3) (a) Férey, G. Chem. Soc. Rev. 2008, 37, 191. (b) Tranchemontagne, D. J.; Mendoza-Cortes, J. L.; O’Keeffe, M.; Yaghi, O. M. Chem. Soc. Rev. 2009, 38, 1257. (c) Horike, S.; Shimomura, S.; Kitagawa, S. Nat. Chem. 2009, 1, 695. (d) Farha, O. K.; Hupp, J. T. Acc. Chem. Res. 2010, 43, 1166. (e) Jiang, H.-L.; Xu, Q. Chem. Commun. 2011, 47, 3351.

(4) (a) Li, J.-R.; Kuppler, R. J.; Zhou, H.-C. Chem. Soc. Rev. 2009, 38 , 1477. (b) Herm, Z. R.; Wiers, B. M.; Mason, J. A.; van Baten, J. M.; Hudson, M. R.; Zajdel, P.; Brown, C. M.; Masciocchi, N.; Krishna, R.; Long, J. R. Science 2013, 340, 960.

(5) (a) Kreno, L. E.; Leong, K.; Farha, O. K.; Allendorf, M.; Van Duyne, R. P.; Hupp, J. T. Chem. Rev. 2011, 112, 1105. (b) Allendorf, M. D.; Bauer, C. A.; Bhakta, R. K.; Houk, R. J. T. Chem. Soc. Rev. 2009, 38, 1330.

(6) (a) Lee, J.; Farha, O. K.; Roberts, J.; Scheidt, K. A.; Nguyen, S. T.; Hupp, J. T. Chem. Soc. Rev. 2009, 38, 1450. (b) Ma, L.; Abney, C.; Lin, W. Chem. Soc. Rev. 2009, 38, 1248. (c) Corma, A.; García, H.; Llabrés i Xamena, F. X. Chem. Rev. 2010, 110, 4606.

(7) (a) Horcajada, P.; Serre, C.; Vallet-Regí, M.; Sebban, M.; Taulelle, F.; Férey, G. Angew. Chem., Int. Ed. 2006, 45, 5974. (b) An, J.; Geib, S. J.; Rosi, N. L. J. Am. Chem. Soc. 2009, 131, 8376. (c) Horcajada, P.; Chalati, T.; Serre, C.; Gillet, B.; Sebrie, C.; Baati, T.; Eubank, J. F.; Heurtaux, D.; Clayette, P.; Kreuz, C.; Chang, J.-S.; Hwang, Y. K.; Marsaud, V.; Bories, P.-N.; Cynober, L.; Gil, S.; Ferey, G.; Couvreur, P.; Gref, R. Nat. Mater. 2010, 9, 172.

(8) Qin, L.; Hu, J.; Zhang, M.; Y, Q.; Li, Y.; Zheng, H. Cryst. Growth Des. 2013, 13, 2111.s.

(9) Cohen, S. M. Chem. Rev. 2012, 112, 970.

(10) (a) Li, T.; Kozlowski, M. T.; Doud, E. A.; Blakely, M. N.; Rosi, N. L. J. Am. Chem. Soc. 2013, 135, 11688. (b) Jeong, S.; Kim, D.; Song, X.; Choi, M.; Park, N.; Lah, M. S. Chem. Mater. 2013, 25, 1047. (c) Bury, W.; Fairen-Jimenez, D.; Lalonde, M. B.; Snurr, R. Q.; Farha, O. K.; Hupp, J. T. Chem. Mater. 2013, 25, 739. (d) Kim, M.; Cahill, J. F.; Su, Y.; Prather, K. A.; Cohen, S. M. Chem. Sci. 2012, 3, 126. (e) Kim, M.; Cahill, J. F.; Fei, H.; Prather, K. A.; Cohen, S. M. J. Am. Chem. Soc. 2012, 134, 18082. (f) Karagiaridi, O.; Bury, W.; Sarjeant, A. A.; Stern, C. L.; Farha,
O. K.; Hupp, J. T. Chem. Sci. 2012, 3, 3256. (g) Burnett, B. J.; Barron, P. M.; Hu, C.; Choe, W. J. Am. Chem. Soc. 2011, 133, 9984.

(11) (a) Deshpande, R. K.; Minnaar, J. L.; Telfer, S. G. Angew. Chem., Int. Ed. 2010, 49, 4598. (b) Lun, D. J.; Waterhouse, G. I. N.; Telfer, S. G. J. Am. Chem. Soc. 2011, 133, 5806. (c) Deshpande, R. K.; Waterhouse, G. I. N.; Jameson, G. B.; Telfer, S. G. Chem. Commun. 2012, 48, 1574. (d) Rankine, D.; Avellaneda, A.; Hill, M. R.; Doonan, C. J.; Sumby, C. J. Chem. Commun. 2012, 48, 10328.

(12) Shultz, A. M.; Sarjeant, A. A.; Farha, O. K.; Hupp, J. T.; Nguyen, S. T. J. Am. Chem. Soc. 2011, 133, 13252.

(13) (a) Mir, M. H.; Koh, L. L.; Tan, G. K.; Vittal, J.J. Angew. Chem., Int. Ed. 2010, 49, 390. (b) Burrows, A. D.; Hunter, S. O.; Mahon, M. F.; Richardson, C. Chem. Commun. 2013, 49, 990.

(14) (a) Karagiaridi, O.; Lalonde, M. B.; Bury, W.; Sarjeant, A. A.; Farha, O. K.; Hupp, J. T. J. Am. Chem. Soc. 2012, 134, 18790. (b) Takaishi, S.; DeMarco, E. J.; Pellin, M. J.; Farha, O. K.; Hupp, J. T. Chem. Sci. 2013, 4, 1509.

(15) (a) RCM in small molecule synthesis. See: Nicolaou, K. C.; King, N. P.; He, Y. Top. Organomet. Chem. 1998, 1, 73. (b) Polymerizations. See: Bielawski, C. W.; Grubbs, R. H. Angew. Chem., Int. Ed. 2000, 39, 2903. (c) Mol, J. C. J. Mol. Catal. A: Chem. 2004, 213, 39. (d) Nuyken, O.; Mueller, B. Des. Monomers Polym. 2004, 7, 215.

(16) Although other catalysts can be used for olefin metathesis, this report will focus on the Ru-based catalysts popularized by Grubbs.

(17) (a) Calderon, N.; Chen, H. Y.; Scott, K. W. Tetrahedron Lett. 1967, 8, 3327. (b) Grubbs, R. H. Tetrahedron 2004, 60, 7117.

(18) (a) Katz, T. J.; Rothchild, R. J. Am. Chem. Soc. 1976, 98, 2519. (b) Bonifacio, M. C.; Robertson, C. R.; Jung, J.-Y.; King, B. T. J. Org. Chem. 2005, 70, 8522. (c) van Otterlo, W. A. L.; de Koning, C. B. Chem. Rev. 2009, 109, 3743.

(19) (a) Iuliano, A.; Piccioli, P.; Davide, F. Org. Lett. 2004, 6, 3711. (b) Donohoe, T. J.; Orr, A. J.; Bingham, M. Angew. Chem., Int. Ed. 2006, $45,2664$.

(20) Farha, O. K.; Malliakas, C. D.; Kanatzidis, M. G.; Hupp, J. T. J. Am. Chem. Soc. 2009, 132, 950.

(21) Although this compound contains some of the mono-Br-mono$\mathrm{NO}_{2}$ derivative, it still leads to the formation of the noninterpenetrated MOF.

(22) Crystals isolated from the reaction were washed with DCE, dried, suspended in $\mathrm{CD}_{3} \mathrm{SOCD}_{3}$, and dissolved using a few drops of $\mathrm{D}_{2} \mathrm{SO}_{4}$. This procedure destroys the framework and allows the characterization of its constituents by ${ }^{1} \mathrm{H}$ NMR spectroscopy.

(23) Starting from the divinyldipyridyl linker 3 or the tetravinyldipyridyl linker 6, direct attempts to synthesize SALEM-13 or SALEM-14, respectively, were not successful, validating the SALE approach.

(24) The 4-chloro-3-vinylpyridine intermediate was purified by silica gel plug filtration and carried forward without further purification. This intermediate is volatile, and purification simply results in the loss of product.

(25) It should be noted that the yield (50\%) for the Miyaura borylation is low because of technical issues that had to be confronted during purification of the product. Silica gel chromatography with $0-5 \%$ $\mathrm{EtOAc/hexanes} \mathrm{was} \mathrm{not} \mathrm{efficient,} \mathrm{and} \mathrm{the} \mathrm{product} \mathrm{had} \mathrm{to} \mathrm{be} \mathrm{crystallized}$ from hot hexanes.

(26) This catalyst was found to be the most reliable at producing product.

(27) When significant amounts of pyridine are used in relation to the catalyst, the reactivity can be impaired. See: (a) Slugovc, C.; Demel, S.; Stelzer, F. Chem. Commun. 2002, 2572. (b) Conrad, J. C.; Fogg, D. E. Curr. Org. Chem. 2006, 10, 185.

(28) In comparison with the structural transformation from $\mathbf{B r}$ YOMOF to SALEM-13 where $2 \theta=3.94$ (Figure 1a,b), $2 \theta=4.76$ (Figure 2a,b) on going from Br-YOMOF to SALEM-14, indicating the incorporation of a shorter pillar, an observation which is in good agreement with the predicted PXRD spectrum (Figure 2c).

(29) Marvin was used for analyzing the relative size of the Grubbs' catalysts, Marvin 6.0.2, 2013, ChemAxon (http://www.chemaxon. com): Minimum projection radius was calculated to be HG1 (6.15 $)$ $<\mathrm{HG} 2(6.68 \AA)<\mathrm{G} 2(7.50 \AA)<\mathrm{G} 1(7.89 \AA)$. 